\title{
A COST-EFFECTIVE SIMPLIFIED ENERGY MONITORING SYSTEM USING IOT
}

Pierre E. Hertzog

Centre for Sustainable Smart Cities, Department of Electrical, Electronics and Computer Engineering.

Central University of Technology, Bloemfontein, (South Africa).

E-mail: phertzog@cut.ac.za ORCID: https://orcid.org/0000-0002-3396-6050

Arthur J. Swart

Centre for Sustainable Smart Cities, Department of Electrical, Electronics and Computer Engineering.

Central University of Technology, Bloemfontein, (South Africa).

E-mail: aswart@cut.ac.za ORCID: https://orcid.org/0000-0001-5906-2896

Recepción: 28/04/2021 Aceptación: 4/06/2021 Publicación: 14/06/2021

\section{Citación sugerida:}

Hertzog, P. E., y Swart, A. J. (2021). A cost-effective simplified energy monitoring system using IOT. 3C Tecnología.

Glosas de innovación aplicadas a la pyme, 10(2), 117-133. https://doi.org/10.17993/3ctecno/2021.v10n2e38.117-133 


\section{ABSTRACT}

The management of any process really requires sensing, transferring and recording of relevant data for analysis purposes so as to make an informed decision. In fact, smart manufacturing requires sufficient knowledge to be available to the decision-maker to ensure that any system runs efficiently and effectively, which may include an energy generation system. The purpose of this paper is to present a simplified energy monitoring system, and its acquired data, that may be used to achieve such real-time results that can be used to make an informed decision. An experimental methodology is applied where empirical quantitative data is derived from a residential home in a suburb of a city having a population of around half a million people. Nine electrical circuits are monitored systematically using a current sensor where data is transferred to Google Sheets using an Arduino microprocessor and ESP8266 module. Custom made power usage graphs are directly visible via any electronic device, for real-time results. It is recommended to make more use of such cost-effective simplified systems in an attempt to provide sufficient knowledge to make an informed decision that may contribute to identifying energy discrepancies in any given system with the aim of improving energy efficiency.

\section{KEYWORDS}

Arduino, Cloud, Energy monitoring, IoT, Cost-Effective. 


\section{INTRODUCTION}

"When I look at the solar system, I see the earth at the right distance from the sun to receive the proper amounts of heat and light. This did not happen by chance" (Brainy Quote, 2020). These words, by Sir Isaac Newton, a world-renowned English Mathematician, well indicate that things do not happen by chance. There must be a designer, a creator, or a maker of some kind to bring forth a system that contains order and stability. In fact, to ensure the ongoing stability, or sustainability, of any designed system requires good management, and not mismanagement.

The term 'management' can be defined as a process of planning, organizing, directing, coordinating and controlling material and non-material, or technology and physical resources toward achieving organizational objectives (Amadike, 2018). The most appropriate definition is of course contingent upon the context in which it is used. However, a key concept should always include monitoring any progress or change.

Effective monitoring requires the systematic collection and analysis of appropriate data (Chapman, 2017) that needs to be transformed into knowledge by linking it with other pockets of information to foster understanding and create meaning (Swart, 2018). Systematic collection needs to be done over a period of time using scientifically validated techniques, where data is processed and presented in meaningful graphs that may contribute to making informed decisions regarding the performance and health of any given concept, or system. In engineering systems, this sensing, transferring, recording and analysing of data is an integral, and indispensable part, of the management process.

How though can this process be implemented in a cost-effective and simplified manner to ensure that systematic data is automatically processed and presented in meaningful graphs over an extended period of time? This is indeed important, as the manual processing of data is often labour-intensive, timeconsuming and extremely costly (Weinstein, 2018). The purpose of this paper is to present a simplified energy monitoring system, and its acquired data, that may be used to present real-time results that can be 
used to make an informed decision about the performance and health of a given system. An experimental methodology is applied where empirical quantitative data is derived for the energy usage in a residential home of a city having a population of around half a million people. The paper firstly commences with a brief discussion of the concept 'smart' and 'IoT' (Internet of Things). The experimental setup, research site, methodology and results then follow. Succinct conclusions round off the paper.

\subsection{THE BIRTH OF 'SMART’ AND 'IOT'}

The term 'smart' as been applied in many different ways, and to many different concepts. It has been stated that it refers to the collection, storage and evaluation of data (Genennig, 2020) where improvements through digital technology can be applied to any process or service (Stolikj et al., 2016). It really implies the automatic collection of desired information that needs to be transformed into meaningful graphs that can be accessed from anywhere and at any time. This information should then be used to automatically execute a command or enable a user to manually perform a required action.

The term "smart" was perhaps first used in the 1990s, with the development of the information society, where the primary emphasis was on ICT (Information and Communication Technologies) in relation to modern infrastructures and their possible impact on society (Das, 2019). Some may assert that the term was made famous by the mobile phone industry with the advent of smartphones during the birth of the 21 st century. Common terms now include "smart city", "smart campus", "smart home" and even "smart student".

Consider just the term "smart city" A Google Scholar search for this exact term reveals some 136000 results. Performing an advanced search where only the title of the article is considered reveals 11900 results, of which almost 9000 occur within the last 5 years (as on 18 March 2020). This term has indeed become a hot topic, or a "buzzword", in academia, business, industry and society at large. 
One could almost say that the term IoT is the twin brother or twin sister of the term 'smart'. Many believe that the term IoT was first coined by Kevin Ashton in 1999 (Darwish et al., 2019), a wellknown British technology pioneer (Tyagi et al., 2019) to refer to a large set of named things that are interconnected (Alagar \& Wan, 2019). Even though the term has been circulating for the past two decades, no commonly accepted definition exists. However, many definitions contain three key concepts, namely sensors, communication and storage. Some or other sensor is used to collect specific data that needs to be communicated to a centralized storage location from where it can be accessed anywhere and at any time.

So, key similarities do exist between the term 'smart' and 'IoT'. However, one could say that the term 'IoT' would focus more on the sharing of information, where the term 'smart' would go one step further and include some or other form of control. Nevertheless, both terms should bring to the mind four key systematic steps, namely sensing, transferring, recording and presentation of relevant data. This may be accomplished by using a cost-effective simplified system, as outlined next.

\subsection{EXPERIMENTAL SETUP}

A cloud-based energy monitoring system was designed as shown in Figure 1. Ten identical current transformer sensors were used to sense ten different electrical circuits in an electrical distribution board of a residential home in a city having a population of around half a million people. The current sensors were coupled to a logging interface circuit that conditions the sensed current signals so that it can be interpreted by the analogue-to-digital converters on an Arduino Mega microcontroller. The microcontroller receives and processes the received signals from the login interface circuit, communicating power values for each individual circuit via serial communication to the ESP8266 WiFi module. The software on this module enables connection to a local WiFi network which facilitates the transfer of data from the Arduino Mega to Google Sheets using a Google script. The recorded data is then analysed and presented in standard graphs available in Google sheets. 


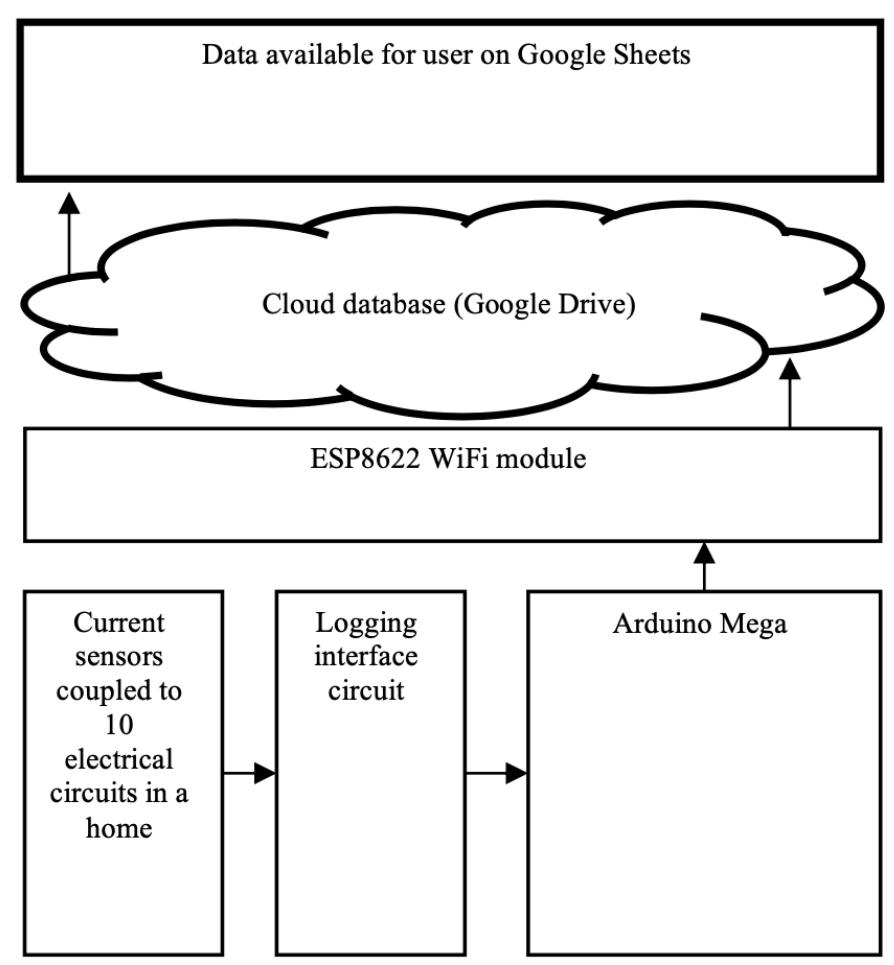

Figure 1. Block diagram of the experimental setup.

Source: own elaboration.

Figure 2 shows the logging interface circuit as well as the ESP8266 WiFi module. The pink wires connect the logging interface circuit to $10 \times 3.5 \mathrm{~mm}$ audio jacks that provide a connection to the current transformer sensors. 


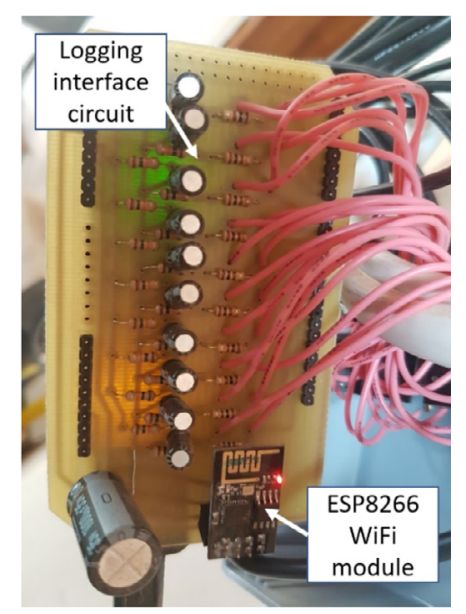

Figure 2. Logging interface circuit and WiFi module.

Source: own elaboration.

In Figure 3, a part of the electrical distribution board of a residential home can be seen. The current transformer (CT current sensor) sensors were firstly coupled to the output of the circuit breakers with no physical interruption in the electrical wires required. This limits the possibility of electrical shock occurring to the installer, as no screwdriver or physical wire connection is required. The transformer current sensor is simply clipped around the relevant current-carrying electrical wire.

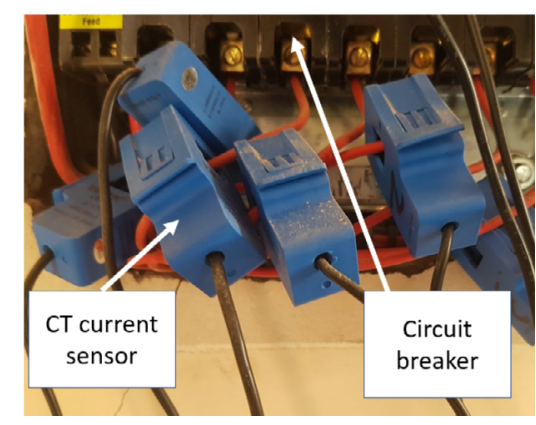

Figure 3. Current sensors and circuit breakers.

Source: own elaboration. 
The current transformer sensors are then plugged into the logging interface circuit where the sensed data is sent to a WiFi module via the Arduino Mega microcontroller. The software program that resides on the Arduino Mega microprocessor includes access details to the local WiFi network of the home, that needs to be modified for other WiFi networks at different research sites.

\section{METHODOLOGY}

The research site for this study is located in Bloemfontein, in the centre of South Africa. This is a semiarid region which is characterized by deep red or yellow sandy loam soils, low annual rainfall, high temperatures and high evaporation (Barnard \& Smith, 2009). It has average daily radiation of between 4.5 and $7 \mathrm{kWh} / \mathrm{m} 2$ with an average annual rainfall of approximately $550 \mathrm{~mm}$ (Mulaudzi et al., 2012).

Bloemfontein was founded in 1896 and currently has an average population of 594428 residents (Mangaung Metro Municipality). It is the capital city of the Free State Province of South Africa. In Dutch, "Bloem" means "flower" and "fontein" means "fountain" (SouthAfrica.TO, 2020). It is also known as the "City of Roses" or Mangaung (which means "place of Cheetahs" in Sesotho). Bloemfontein is also home to South Africa's Appeal Court.

An experimental study is undertaken where data was collected for 6 months, from June 2018 to December 2018. Experimental studies are usually subject to many factors, eg, materials, equipment, and costs, and therefore limit the research speed (Zhang et al., 2018). The equipment associated with this study includes nine current transformer sensors, a logging interface circuit, an Arduino Mega microprocessor and an ESP8266 module that tallies a total cost of around $\$ 130$. Ten electrical circuits in an averaged sized residential home was sampled. This home consists of a living area (including 3 bedrooms), two guest rooms, laundry room, an office, a kitchen and an outside aquaponics system. Two geysers rated at $2 \mathrm{~kW}$ each, also exist on the property. 


\section{RESULTS}

The experimental setup was used to record the power consumption of nine electrical circuits in an average sized residential home. In order to make informed decisions regarding the power usage, the sampling period for the data was set to 10 minutes. Figure 4 presents the power consumption recorded for a one-day period. The kitchen used $17.8 \%$ of the total power, which excludes the stove that was monitored separately $(3.1 \%$ for the stove that brings the total power consumption for the kitchen to $20.9 \%$ ). The aquaponics system, featuring two electrical pumps, consumed $20.8 \%$ of the total power for that day. The office that also includes an air conditioner consumed $16.9 \%$ of the total power.

The two hot water geysers used 12.4 and $9.2 \%$ of the total power. This is different from previous research published in 1992 that showed that some geysers consume approximately $45 \%$ of the total electricity used in homes (Meyer et al., 1992). However, a 2016 study in Norway showed that newer geysers consume 10\% of household electricity consumption (Shan et al., 2016). The lower percentage power usage by the geysers may be attributed to the fact that the geysers are well isolated and that the total power used would be higher than a home that does not have an aquaponics system, that consumed one fifth of the total power.

The total power consumption for both geysers dedicated to water heating was $21.6 \%$. The rest of the power consumption was spread between the guest rooms $(11.1 \%)$, laundry room $(1 \%)$ and the living area (7.7\%).

Figure 5 shows the total recorded power curve for the one-day period. The maximum power that was drawn around 4 a.m. can be attributed to the timer that switches both geysers on as residents awake and start preparing for the days' work ahead. A second significant spike around 1:30 p.m. can be attributed to appliances in the kitchen as lunch is prepared. 


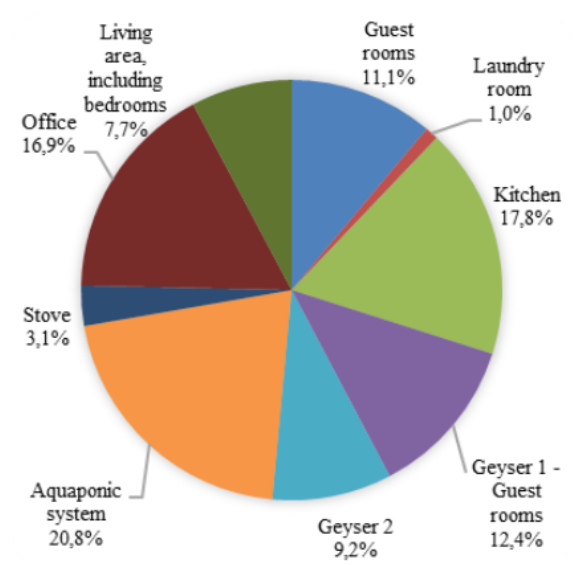

Figure 4. Distribution of recorded power consumption for one day.

\section{Source: own elaboration.}

The percentage power consumption distribution of the nine electrical circuits for a six-month period is visible in Figure 6. It is noteworthy that its distribution is similar to that for the six-month period. This relates to the validity of the simplified cost-effective energy monitoring system and reliability of the data. Reliability refers to the consistency, stability and repeatability of results while validity refers to the degree to which a test, or system, appears to measure what it claims to measure (Mohajan, 2017). For instance, the one-day consumption for the guest room was $11.1 \%$ in Figure 4 , and $10.7 \%$ for the six-month period in Figure 6. The aquaponics system power consumption varied with $0.5 \%$ from $20.8 \%$ for one-day to $20.3 \%$ for the six-month period. Similar results are observed for the living area. 




Figure 5. Recorded power profile for one day.

Source: own elaboration.

There was a slightly larger difference in the power consumption for the kitchen, being $17.8 \%$ on oneday and $14.1 \%$ over the six-month period. However, a significant difference in power consumption was determined for geyser 2 , being $9.2 \%$ for one-day and $14.8 \%$ over the six-month period. This may be attributed to the fact that this geyser is older than geyser one and may not be as well isolated. New water heaters (or geysers) are much more energy-efficient than older models and replacing one that is 7 years old is a good idea (Smith, 2019). Almost all new units have a 2-inch-thick polyurethane foam in their jacket that contributes significantly to an improvement in thermal insulation. 


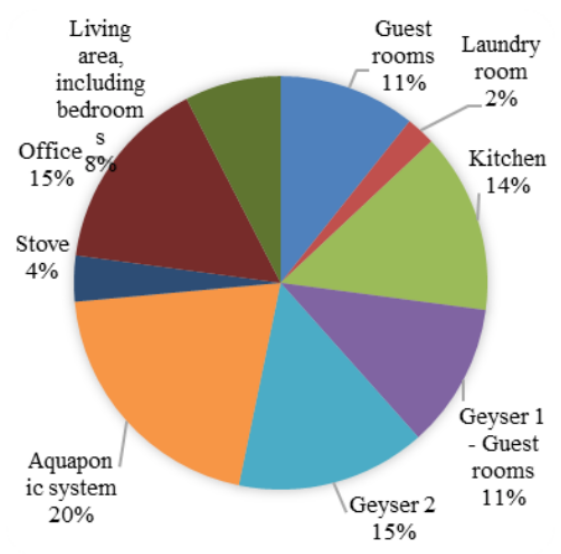

Figure 6. Distribution of recorded power for a six-month period.

\section{Source: own elaboration.}

Furthermore, the six-month period was from June 2018 to December 2018, which included a significant portion of the winter period. Geysers are known to require higher amounts of thermal energy in winter than in summer, due to the temperature difference of the water that needs to be heated (Kalogirou, 2009). More energy consumption would therefore be required in the winter period (June to July) than in the summer period (November to December). The percentage difference between the on-day and sixmonth power consumption data for the nine circuits can be seen in Figure 7. 


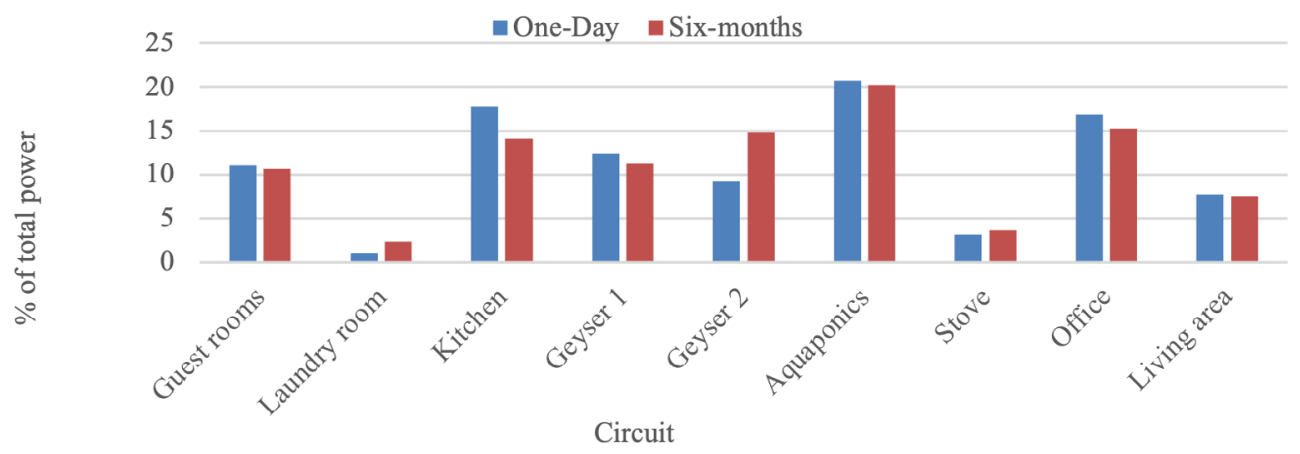

Figure 7. The percentage difference between the one-day and six-month power consumption data.

Source: own elaboration.

\section{CONCLUSIONS}

The purpose of this paper was to present a simplified energy monitoring system, and its acquired data, that may be used to present real-time results that can be used to make an informed decision about the performance and health of a given system. The results from this study showed that the energy monitoring system is indeed reliable, as consistent power consumption readings were obtained over a period of six-months that reflect the power consumption of a one-day period. This was determined for the living room, two guest rooms, laundry room, office, kitchen and an aquaponics system. However, a $5.6 \%$ difference was determined for the main geyser in the home, that may be attributed to its age or the change in season, where more electrical energy is required in winter than in summer to heat the water to a pre-determined temperature. It is recommended to make more use of such cost-effective simplified systems in an attempt to provide sufficient knowledge to make an informed decision that may contribute to identifying energy discrepancies in any given system with the aim of improving energy efficiency. 


\section{REFERENCES}

Alagar, V., \& Wan, K. (2019). Understanding and Measuring Risk due to Uncertainties in IoT. In 2019 IEEE International Conference on Smart Internet of Things (SmartIoT), 484-488. https://doi. org/10.1109/SmartIoT.2019.00088

Amadike, G. M. (2018). The Effect Of Recruitment And Selection Policy As A Tool For Achieving Higher Employee Productivity In Manufacturing Organizations: A Study Of Dozzy Group Of Companies (Thesis). Amadike, Chinaza Marypamela. http:/ / eprints.gouni.edu.ng/571/

Barnard, A. \& Smith, M. F. (2009). The effect of rainfall and temperature on the preharvest sprouting tolerance of winter wheat in the dryland production areas of the Free State Province. Field Crops Research, 112(2-3), 158-164. https://doi.org/10.1016/j.fcr.2009.02.011

Brainy Quote. (2020). Homepage. http://www.brainyquote.com/quotes/

Chapman, A. R. (2017). A "Violations Approach" for Monitoring the International Covenant on Economic, Social and Cultural Rights 1. Human Rights. Routledge.

\section{Darwish, A., Hassanien, A. E., Elhoseny, M., Sangaiah, A. K., Muhammad, K., \& Computing,}

H. (2019). The impact of the hybrid platform of internet of things and cloud computing on healthcare systems: opportunities, challenges, and open problems. Fournal of Ambient Intelligence, 10, 4151-4166. https://doi.org/10.1007/s12652-017-0659-1

Das, D. (2019). Smart City. In Orum, A. (ed.) The Wiley Blackwell Encyclopedia of Urban Regional Studies. John Wiley and Sons.

Genennig, S. M. (2020). Research Context: Foundations of the Research. Realizing Digitization-Enabled Innovation. Springer. 
Kalogirou, S. (2009). Thermal performance, economic and environmental life cycle analysis of thermosiphon solar water heaters. Solar energy, 83(1), 39-48. https://doi.org/10.1016/j. solener.2008.06.005

Mangaung Metro Municipality. (2019). Integrated Development Plan 2018/19 http://www.mangaung. co.za/2019/04/09/draft-integrated-development-plan-2019-20-idp-sectoral-plans-mtrefbudget-2019-20-2021-22-budget-related-policies/

Meyer, J. P., \& Greyvenstein, G. (1992). Influence of price changes on the viability of heat pumps for heating water in South African homes. Energy conversion, 33(1), 41-49. https://doi. org/10.1016/0196-8904(92)90145-M

Mohajan, H. K. (2017). Two criteria for good measurements in research: Validity and reliability. Annals of Spiru Haret University. Economic Series, 17(4), 59-82. https://doi.org/10.26458/1746

Mulaudzi, S. K., Muchie, M., \& Makhado, R. (2012). Investigation of the solar energy production and contribution in South Africa: research note. African Fournal of Science, Technology, Innovation and Development, 4, 233-254. https://www.researchgate.net/publication/262527564_Investigation_ of_the_Solar_Energy_Production_and_Contribution_in_South_Africa

Shan, K., Wang, S., Yan, G., \& Xiao, F. (2016). Building demand response and control methods for smart grids: A review. Science and Technology for the Built Environment, 22(6), 692-704. https://doi.org /10.1080/23744731.2016.1192878

Smith, B. (2019). Tucson regional strategies toward a more sustainable home. The University of Arizona.

Southafrica.TO. (2020). Bloemfontein https://www.southafrica.to/provinces/FreeState/towns/ Bloemfontein/Bloemfontein.php

Stolikj, M., Lukkien, J. J., Cuijpers, P. J., \& Buchina, N. (2016). Nomadic service discovery in smart cities. Smart Cities and Homes. Elsevier. 
Swart, A. J. (2018). An Analysis of Master Dissertations: A Case Study of Central University of Technology, South Africa. AJLAIS, African Fournal of Library, Archives and Information Sciences, 28(2), 211-223. https://www.ajol.info/index.php/ajlais/article/view/183188

Tyagi, S., Joshi, M., Ansari, N., Singh, V., \& Data, B. (2019). Impact of IoT to Accomplish a Vision of Digital Transformation of Cities. In Solanki, V. K., Díaz, V. G. \& Davim, P. (eds.) Handbook of IoT.

Weinstein, B. G. (2018). A computer vision for animal ecology. Fournal of Animal Ecology, 87(3), 533-545. https://doi.org/10.1111/1365-2656.12780

Zhang, Y., Zhang, N., \& Ge, G. (2018). First-Principles Studies of Adsorptive Remediation of Water and Air Pollutants Using Two-Dimensional MXene Materials. Materials, 11(11), 2281. https:// doi.org/10.3390/mal1112281 
